\section{El valor de las bibliotecas en España triplica su coste \\ Hilario Hernández-Sánchez}

\author{
Análisis y Estudios \\ Fundación Germán Sánchez Ruipérez \\ hilario.hernandez@fundaciongsr.es
}

Hernández-Sánchez, Hilario (2015). "El valor de las bibliotecas en España triplica su coste". Anuario ThinkEPI, v. 9, pp. 97-98

http://dx.doi.org/10.3145/thinkepi.2015.17

Publicado en Blok de BiD el 19 de febrero de 2014

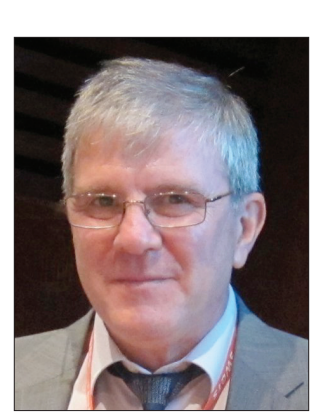

Worth every cent
and more..., Worth their
weight..., Enriching com-
munities..., The Library divi-
dend..., Dollars, sense and
public libraries... 1 . Títulos
tan sugestivos figuran en
las portadas de algunos de
los estudios que se vienen
realizando en los últimos
años y que tratan de medir el impacto económico y social de las bibliotecas. La inmensa mayoría de ellos se han elaborado principalmente en los Estados Unidos, en el Reino Unido y en Australia. No faltan algunas aproximaciones en otros países (Alemania, Nueva Zelanda, Noruega, Corea, Canadá...), a los que se ha incorporado en el último año España.

En la base de estos informes está la crisis de la financiación pública $y$, por tanto, la necesidad de mostrar el valor social y económico de los servicios bibliotecarios. Aunque han sido realizados con métodos distintos, no hay aún una terminología uniforme, ni unas herramientas e indicadores unificados y homologados, se están produciendo intentos de normalización y tiende a haber una confluencia progresiva, al menos en lo que se refiere al objetivo de mostrar el valor económico de las bibliotecas y su impacto en la economía general y local, con evaluación del costo/beneficio o del retorno de la inversión (ROI) en términos monetarios.

Lo habitual es que en el diseño, realización, análisis y comunicación de estos estudios participe un equipo relativamente interdisciplinar (economistas, bibliotecarios, sociólogos, responsables institucionales...).

En esta línea se encuentra el estudio El valor económico y social de los servicios de información: bibliotecas presentado el 17 de enero de 2014, un trabajo promovido por Fesabid, en el marco del I Plan estratégico del Consejo de Cooperación Bibliotecaria 2013-2015, y del que ya se presentó un avance de resultados en las jornadas de Fesabid de Toledo en mayo de 2013. Precisamente en Toledo se presentó también otro estudio de este tipo, el primero del que se tiene referencias en España: "El retorno a la inversión de la Red de Bibliotecas Municipales de la provincia de Barcelona (2007-2011)", por Maria Luria-Roig y Joël Pintor-González, publicado en las actas de Fesabid 2013.

http://www.fesabid.org/toledo2013/noticialactasvideos-y-presentaciones-del-congreso

El estudio de Fesabid ha sido coordinado por el sociólogo José-Antonio Gómez-Yáñez y realizado por el Estudio de Sociología Consultores. Su finalidad, tal como declara en su presentación la presidenta de Fesabid, Margarita Taladriz, ha sido "poder mostrar y demostrar, con datos basados en evidencias y no simplemente en percepciones, el valor que se aporta a la sociedad y a

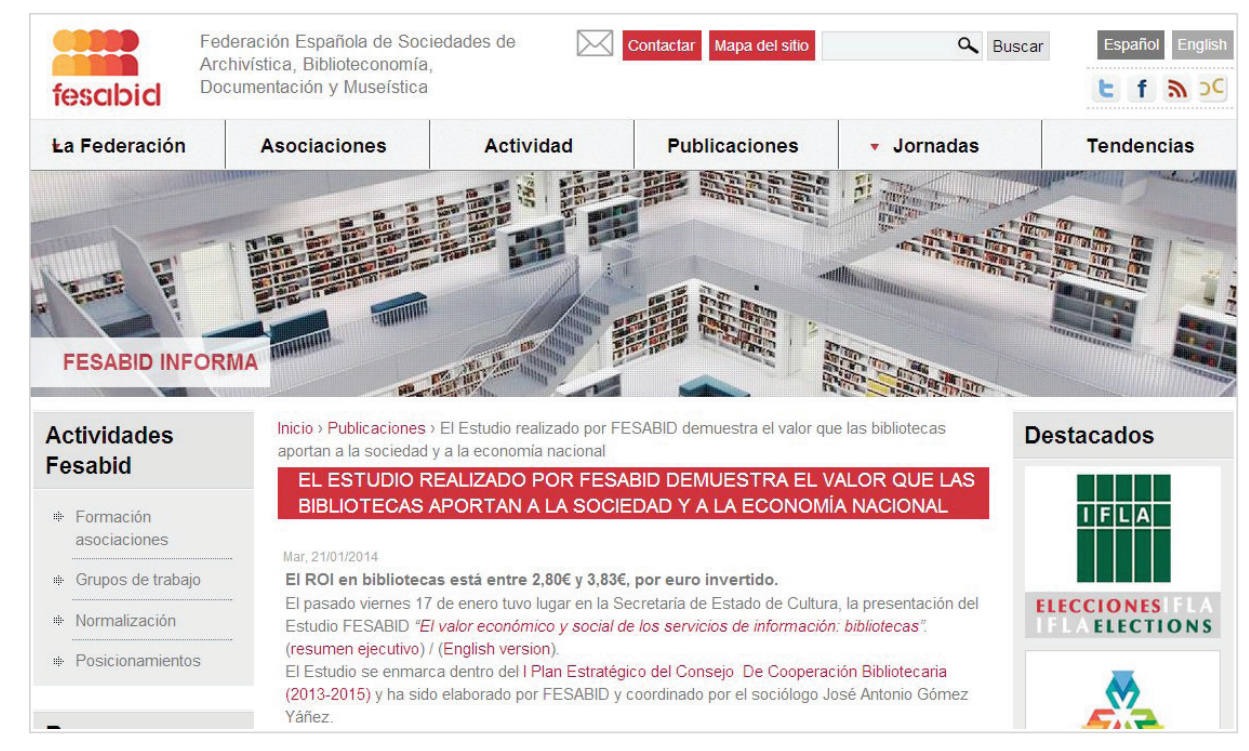


la economía nacional desde estos servicios públicos, que no son, como se demuestra, un centro de gasto, sino una inversión rentable".

El objetivo es pues ambicioso, tanto como el ámbito de análisis, que incluye todo tipo de bibliotecas, aunque en la práctica se centra fundamentalmente en las bibliotecas públicas, universitarias y científicas. $Y$ sobre las mismas construye su conclusión más importante: por cada euro asignado para gastos o inversión en las bibliotecas, estas retornan un valor que se sitúa entre 2,80 y 3,83 euros. Dicho de otra manera: si los gastos anuales de las bibliotecas ascienden a 1.107,2 millones de euros (INE, 2010), el valor de sus servicios para los ciudadanos se estima en 3.099,8 millones de euros si a estos servicios se les asignara un precio de mercado (método de analogía con el mercado o de asignación de precios de mercado), o ascendería a 4.238,5 millones de euros si fueran prestados por empresas privadas (método de valoración contingente).

Además de estas y otras estimaciones económicas, la investigación se estructura como un amplio estudio de usuarios. Así, recoge el valor social (e indirectamente monetario) que los profesionales

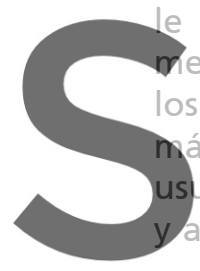
otorgan a los servicio entales. De la misma mar os no usuarios ante las bib específica, los usos uarios respectivos ante las ante las universitarias y cir

Se destaca, como novedoso, la conexión entre el quehacer de los investigadores y la aportación

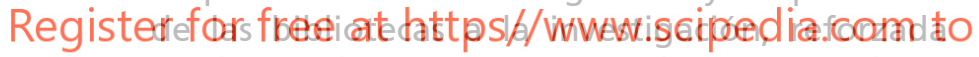
por la muy buena opinión que los investigadores declaran sobre los profesionales de las bibliotecas y la información que se localiza en ellas.

Para la realización del estudio se han utilizado varias metodologías y se han realizado distintos trabajos de campo, entre otros:

- recopilación y explotación de la información estadística disponible, de INE (la más reciente de 2010) y de Rebiun;

- estudio de gabinete para la estimación y asignación de precios de mercado;

- cuatro reuniones de grupo con profesionales de bibliotecas, centros de documentación y archivos;

- una encuesta telefónica a población no usuaria de bibliotecas, entre los 18 y 75 años (diciembre de 2012); y, por último,

- dos encuestas online con acceso voluntario, una con 633 entrevistas a usuarios de bibliotecas públicas (junio-julio de 2013) y otra con 337 entrevistas a usuarios de universitarias y científicas (septiembre-octubre de 2013).

Se ha abierto, en definitiva, una línea de investigaciones y estudios que puede aportar informaciones y perspectivas de enorme interés. Poner de relieve el impacto económico y social de los servicios bibliotecarios es sin duda una tarea que puede llegar a ser imprescindible en las actuales y futuras circunstancias de limitaciones presupuestarias. Al estudio promovido por Fesabid y al mencionado estudio realizado por la Diputación de Barcelona, cabe esperar que se le sumen, en un plazo breve, los resultados del grupo de trabajo para el Estudio de impacto socioeconómico de las bibliotecas ${ }^{2}$ y los de otras posibles iniciativas en sectores o territorios concretos, que muestren y difundan de qué forma y hasta qué punto los beneficios socioeconómicos generados por las bibliotecas son superiores a los costes que generan.

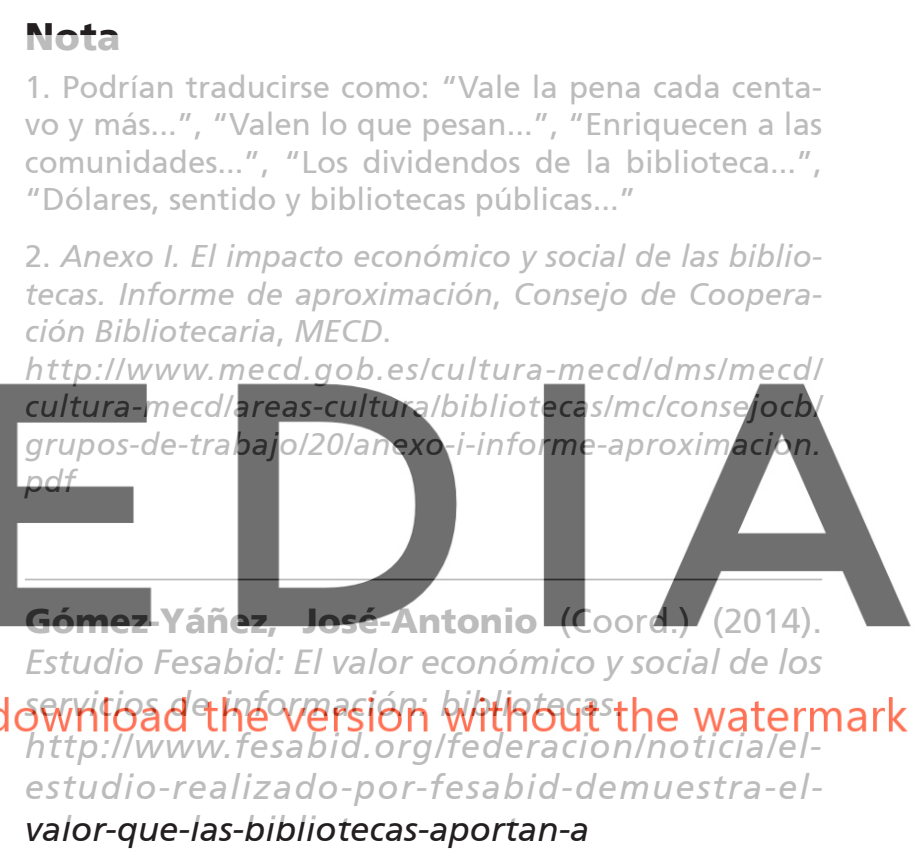

Nota original completa en Blok de BiD: http://www.ub.edu/b/okdebid/es/node/457

\section{Nacidas digitales Isabel Bordes-Cabrera}

Área de Biblioteca Digital Biblioteca Nacional de España isabel.bordes@bne.es

Bordes-Cabrera, Isabel (2015). "Nacidas digitales". Anuario ThinkEPI, v. 9, pp. 98-100.

http://dx.doi.org/10.3145/thinkepi.2015.18

Publicado en Blok de BiD el 16 de abril de 2014 